\title{
A Novel Electrically Small Meandered Line Antenna with a Trident-Shaped Feeding Strip for Wireless Applications
}

\author{
Xueyao Ren, Xing Chen, and Kama Huang \\ College of Electronics and Information, SiChuan University, Chengdu 610064, China \\ Correspondence should be addressed to Xing Chen, xingch@263.net
}

Received 6 April 2012; Revised 7 June 2012; Accepted 17 June 2012

Academic Editor: Leena Ukkonen

Copyright () 2012 Xueyao Ren et al. This is an open access article distributed under the Creative Commons Attribution License, which permits unrestricted use, distribution, and reproduction in any medium, provided the original work is properly cited.

\begin{abstract}
A novel electrically small antenna (ESA) which based on the meandered line structure is designed, fabricated, and measured. The proposed antenna whose total size is $13.50 \mathrm{~mm} \times 13.51 \mathrm{~mm} \times 0.8 \mathrm{~mm}$ is designed to cater for the ISM (industrial, scientific, and medical) band of $2.45 \mathrm{GHz}$ with a $S_{11}<-10 \mathrm{~dB}$ bandwidth of $3.9 \%$. By introducing a trident-shaped feeding strip and inserting 4 pairs of triangular slot stubs at the central feed line, the resonant frequency of the antenna drops to $2.45 \mathrm{GHz}$ from $2.50 \mathrm{GHz}$ and the impedance matching is improved significantly. The dimension parameters of this antenna are optimized to achieve wide impedance bandwidth, reasonably high gain, as well as omnidirectional radiation pattern.
\end{abstract}

\section{Introduction}

Recently, wireless communication has become more and more widespread. As compact wireless communication systems become a greater focus in our lives, the demand for small-size and high-performance antennas escalates. Therefore, antenna miniaturization has received significant attention in the latest years.

For an antenna which is categorized to electrically small, it should fulfill the definition: $k a<0.5$, where $k$ is defined as the free space wave number and $a$ the radius of the sphere inclosing the maximum dimensions of the antenna $[1,2]$. The size reduction of antennas will result in the performance degradation such as narrow bandwidth, high voltage standing wave ratio (VSWR), low gain, among others. Accordingly, the key of designing an electrically small antenna is always an art of compromise among size, bandwidth, and gain.

Numerous designs of electrically small antenna have been presented in the recent literatures, such as the disk-loaded monopole antenna [3], inductively coupled feed antenna [4], arbitrarily shaped wire antennas designed by genetic algorithms (GA) [5, 6], folded monopoles and meandered dipoles $[7,8]$, resistively or reactively lumped components loading antennas $[9,10]$, metamaterial-based electrically small antennas $[11,12]$, superconducting electrically small antennas $[13,14]$, among others. It is noted that most of their structures are complicated, which increases manufacturing difficulty and cost. Some of them are not planar structures that are suitable for connected with monolithic microwave integrated circuit (MMIC). Some of them must work together with external inductors or capacitors, which cause extraohmic losses that could be critical for some applications. Some of them are born with narrow bandwidth which is less than $1 \%$ because the permeability or permittivity of the metamaterial could be zero only in a particular frequency. Others might meet the strict definition of ESA but only under rigorous conditions, for example, superconductivity.

The coplanar waveguide- (CPW-) fed antennas have many attractive features, such as low radiation loss, less dissipation, easy fabrication, and integration with MMIC without any need of via holes as used in microstrip technology.

In this paper, a novel electrically small antenna with a trident-shaped feeding strip is proposed. The tridentshaped feeding strip is introduced to reduce the electrical size of the antenna. At the same time, 4 pairs of triangular slot stubs are used to improve the performance in terms of bandwidth. Section 2 describes the configuration of the proposed antenna. Section 3 includes numerical results simulated by the software Ansoft High Frequency Structure Simulator (HFSS) [15] which is based on 3D full-wave finite-element method (FEM). To examine the antenna 


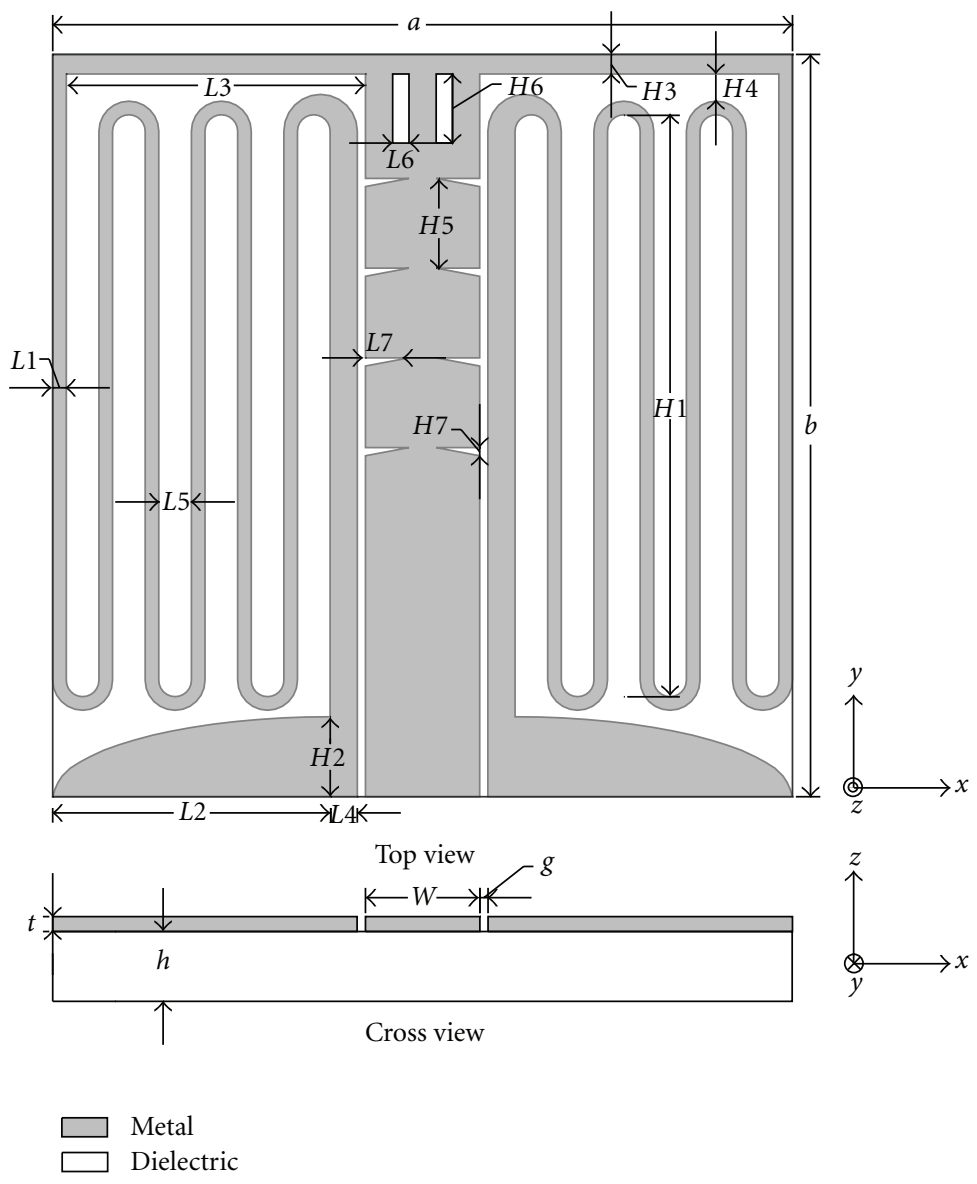

FIGURE 1: Geometry configuration of proposed antenna.

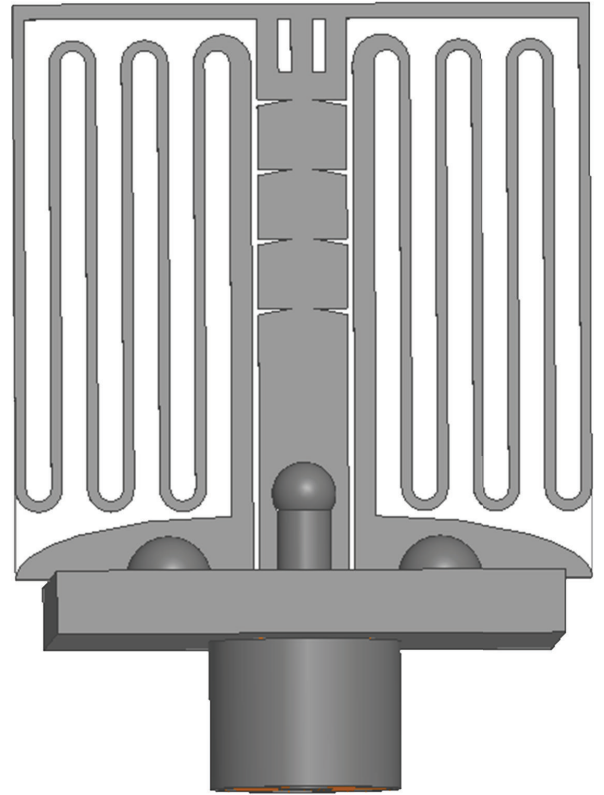

(a)

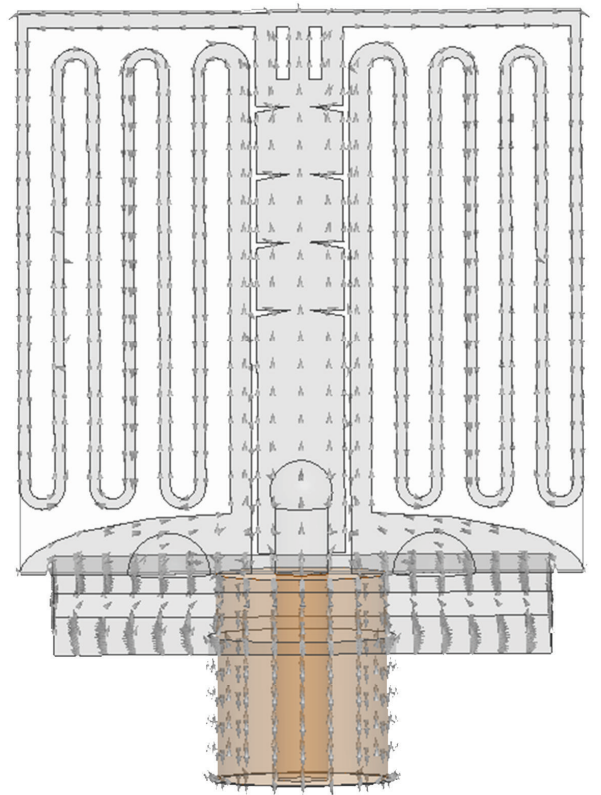

(b)

FIGURE 2: The simulation model of the proposed antenna and the surface current distribution. 


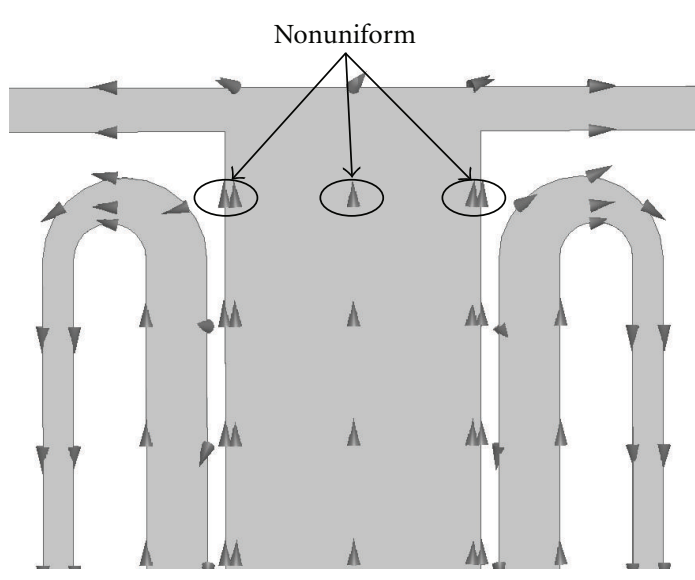

(a)

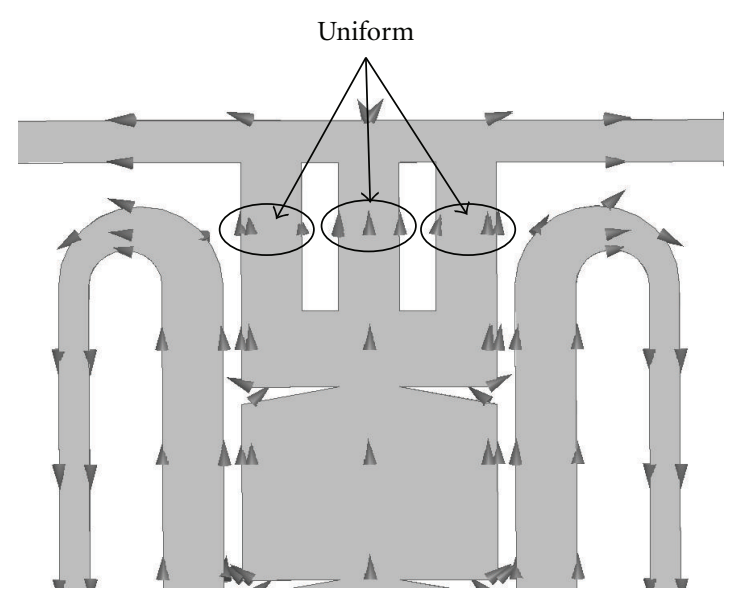

(b)

FIgURE 3: (a) A common CPW feeding line (b) A CPW feeding line with a trident-shaped feeding strip and triangular slot stubs.

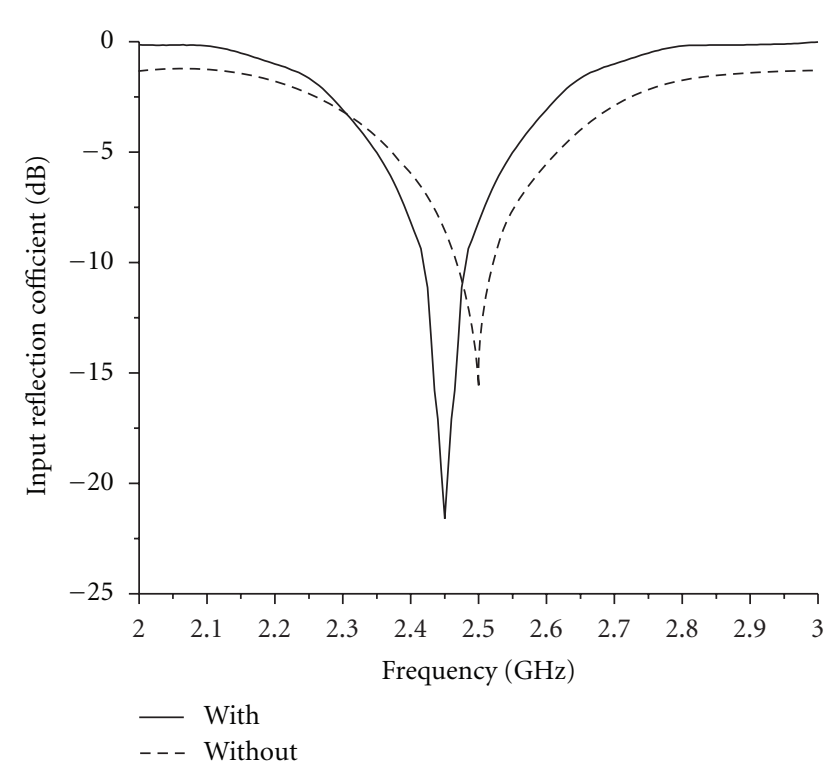

FIGURE 4: Input reflection coefficient comparison of the antenna with or without a trident-shaped feeding strip and 4 pairs of triangular slot stubs.

performance, experimental results are also involved and discussed.

\section{Antenna Configuration}

The geometry configuration of the proposed CPW-fed antenna is shown in Figure 1. The antenna is based on nongrounded coplanar waveguide which has a single-layer metallic structure (thickness $t=0.018 \mathrm{~mm}$ ) and etched on a side of an FR-4 substrate. The selected substrate material is Rogers RO4003C [16] with a dielectric constant $\varepsilon_{r}=3.38$ and thickness $h=0.8 \mathrm{~mm}$. The overall dimension of the proposed antenna is $13.50 \mathrm{~mm} \times 13.51 \mathrm{~mm}$. A $50 \Omega \mathrm{CPW}$ central transmission line of strip with width $W=2 \mathrm{~mm}$ and gap $g=0.15 \mathrm{~mm}$ is used for feeding the antenna.
This antenna is based on two meandered parallel resonant arms whose lengths are $H 1$ and widths are $L 1$ to further reduce the antenna dimensions because this meandering leads to an extended current path for a fixed length, so that the antenna seems electrically larger [17]. The latitudinal distance between two meandered arms is L5. There is a strip whose length is $L 3$ and width is $H 3$, connecting the central transmission line to the two meandered arms. Onequarter of elliptical ground is introduced to improve the impedance bandwidth. Lengths of the semimajor axis and the semiminor axis of this elliptical ground are $L 2$ and $H 2$ respectively. A tapered parallel arm with length $H 1$, width $L 4$ is used to realize impedance transformation between ground and meandered parallel resonant arm. By inserting a pair of longitude direction's symmetrical slots whose lengths are $\mathrm{H} 6$ and widths are $L 6$, a trident-shaped feeding strip is achieved. The impedance matching is improved significantly by using this trident-shaped feeding strip working with 4 pairs of triangular slot stubs whose lengths are $L 7$ and widths are $H 7$. The longitudinal distance between each pair of triangular slot stubs is H5. Finally, the other dimensions of the proposed antenna are optimized as follow: $a=13.50 \mathrm{~mm}, b=$ $13.51 \mathrm{~mm}, L 1=0.25 \mathrm{~mm}, H 1=10.70 \mathrm{~mm}, L 2=5.10 \mathrm{~mm}$, $H 2=1.45 \mathrm{~mm}, L 3=5.50 \mathrm{~mm}, H 3=0.36 \mathrm{~mm}, L 4=$ $0.50 \mathrm{~mm}, H 4=0.50 \mathrm{~mm}, L 5=0.60 \mathrm{~mm}, H 5=1.65 \mathrm{~mm}$, $L 6=0.25 \mathrm{~mm}, H 6=1.27 \mathrm{~mm}, L 7=0.75 \mathrm{~mm}, H 7=$ $0.15 \mathrm{~mm}$.

\section{Antenna Design}

The whole antenna mounting structure of the simulation model, including its driving connector and the corresponding surface current vector distribution are shown in Figure 2. Three metal balls were used to simulate the solder joints.

A key idea of the proposed novel feeding structure can be most conveniently explained by consideration of an equivalent current path on the metallic conductor which can be seen in Figure 3. It is seen from Figure 3(a) that most of the current focuses on both sides of the central feeding 


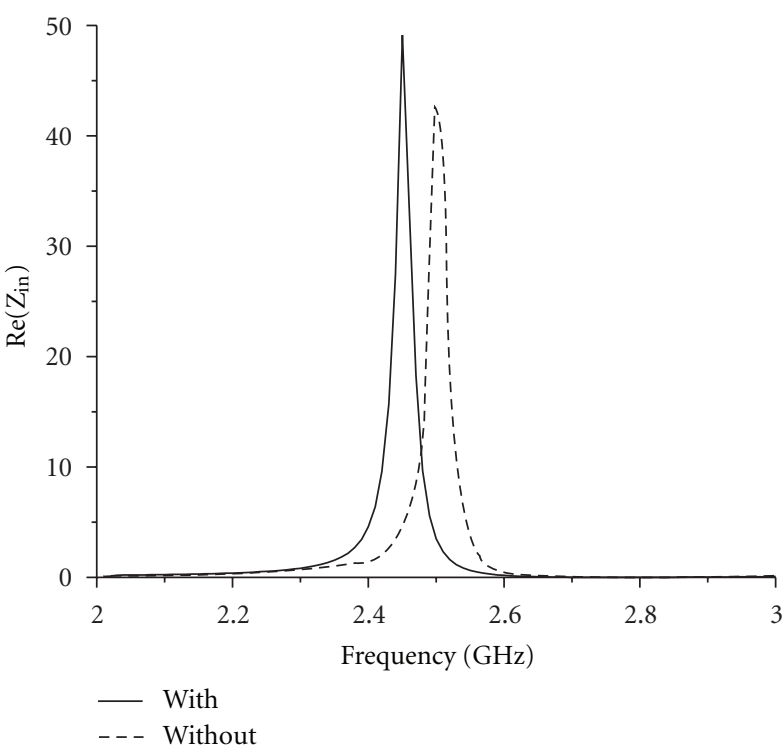

(a)

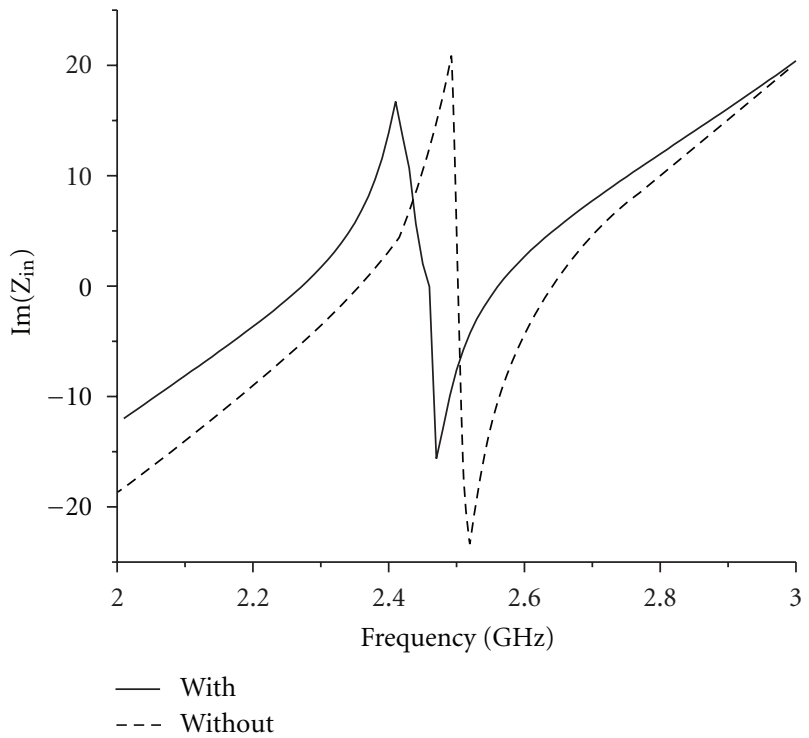

(b)

FIGURE 5: Input impedance comparison of the antenna with or without a trident-shaped feeding strip and 4 pairs of triangular slot stubs.

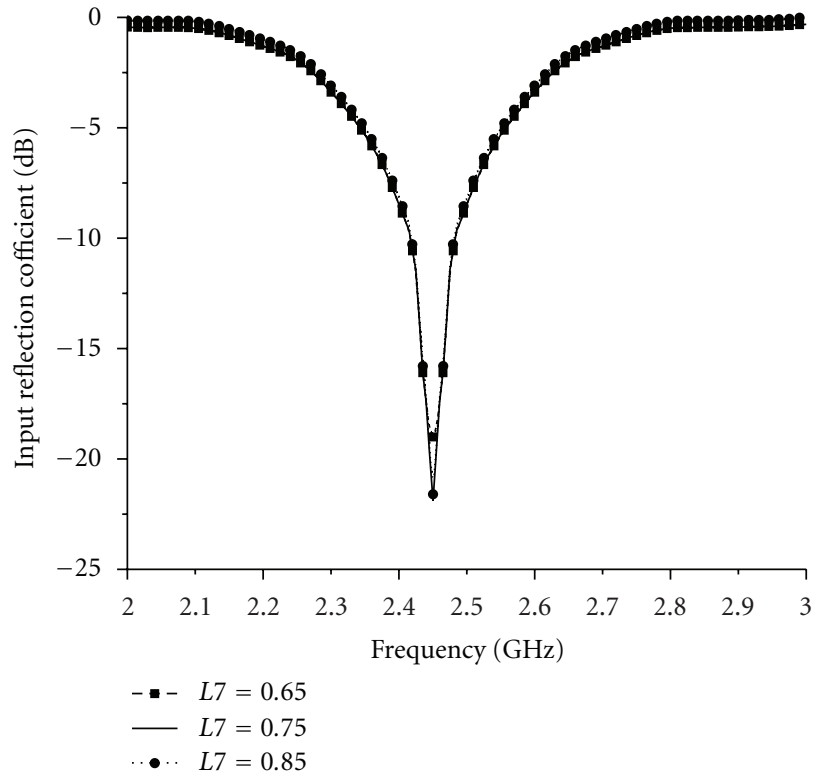

(a)

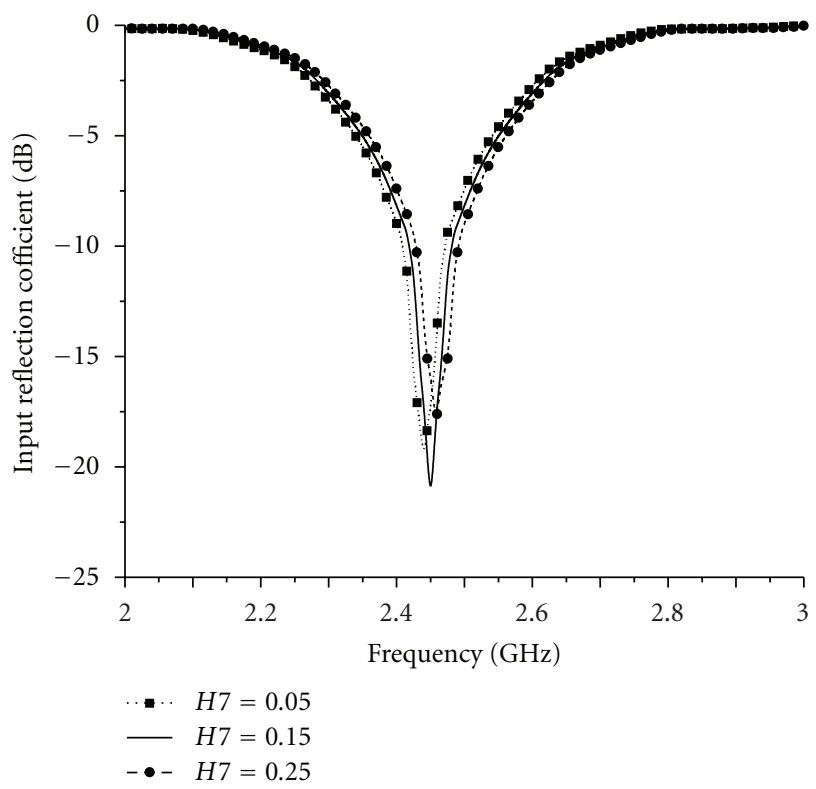

(b)

FIGURE 6: The input reflection coefficient changes with the length $L 7$ and width $H 7$.

line because the radiation is along the slot of CPW structure. The current distributions between the middle and both sides are nonuniform. It is also seen from Figure 3(b) that, the middle current distribution becomes more uniform due to a trident-shaped feeding structure which is used to shunt the current that focus on both sides of the central feeding line, and increase current that flows to two meandered arms from middle. As a result, the equivalent path of current distribution becomes slightly longer for a fixed dimension. So the resonant frequency of the antenna from $2.50 \mathrm{GHz}$ drops to $2.45 \mathrm{GHz}$.
However, this structure changes the antenna to unbalance. By adding 4 pairs of triangular slot stubs symmetrically on each side of the central CPW feeding line, the impedance matching condition is improved observably, which is shown in Figure 4.

Figure 4 illustrates the computed input reflection coefficient of the common CPW feeding antenna (dash line) in comparison with that of the antenna having the novel feeding structure (solid line). It observed that $S_{11}<-10 \mathrm{~dB}$ bandwidth of the antenna with proposed feeding structure amounts to $65 \mathrm{MHz}$ from $2.415 \mathrm{GHz}$ to $2.480 \mathrm{GHz}$ with 


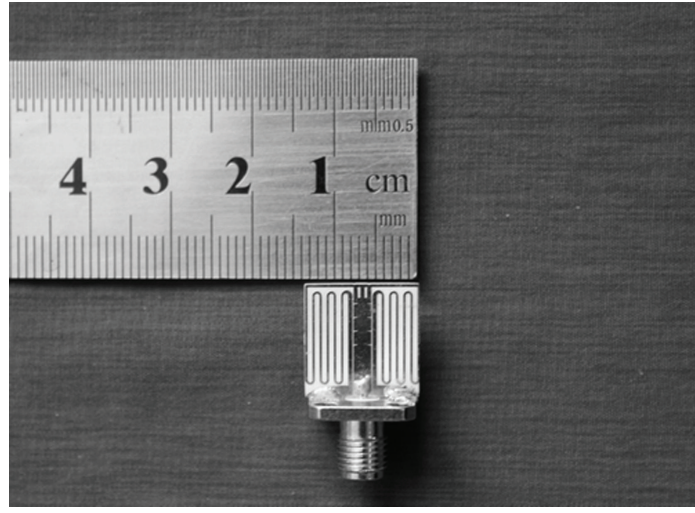

(a)

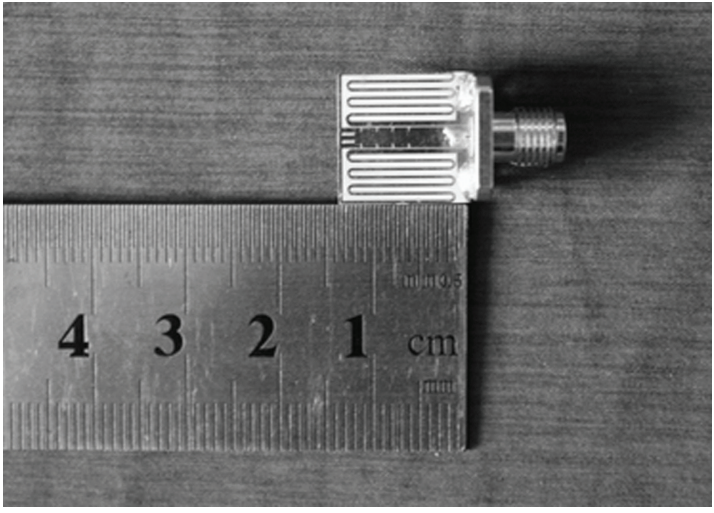

(b)

FIGURE 7: The prototype of the proposed antenna (a) top view (b) side view.

the center frequency at $2.45 \mathrm{GHz}$, while the corresponding bandwidth of the common CPW antenna is $45 \mathrm{MHz}$ from $2.470 \mathrm{GHz}$ to $2.515 \mathrm{GHz}$ with the center frequency at $2.50 \mathrm{GHz}$. Thus, the $S_{11}<-10 \mathrm{~dB}$ bandwidth of novel antenna is wider by $44 \%$ than the common one. At the same time, the electrical size of the antenna $k a$ drops to 0.49 from 0.50 . As proven above, the bandwidth enhancement and impedance matching condition have been achieved exclusively owing to the trident-shaped feeding strip and the triangular slot stubs, the changes of input impedance with or without the trident-shaped feeding strip and the triangular slot stubs are shown in Figure 5. The changes of input reflection coefficient with the length $L 7$ and width $H 7$ of the slot-stubs can be seen in Figure 6. One can observe that the length $L 7$ has little effect on input reflection coefficient, while the width $H 7$ has a major influence on it.

\section{Results and Discussion}

To validate the theoretical design, a prototype of the antenna has been fabricated which shown in Figure 7. The input reflection coefficient of the fabricated electrically small antenna has been measured by an Agilent N5230A Network Analyzer.

Measured input reflection coefficient and the computed one by simulation are shown in Figure 8.

The designed resonant frequency of the proposed antenna is $2.45 \mathrm{GHz}$, the measured one, shown in Figure 8, is observed at $2.46 \mathrm{GHz}(0.4 \%$ error). It also can be seen that the antenna has a good match at $2.46 \mathrm{GHz}$ with an input reflection coefficient of $-30.80 \mathrm{~dB}$. The measured $S_{11}<$ $-10 \mathrm{~dB}$ bandwidth is $95 \mathrm{MHz}$ from $2.410 \mathrm{GHz}$ to $2.505 \mathrm{GHz}$, corresponding to $3.9 \%$ of the center frequency versus the simulated one $2.7 \%$ from $2.415 \mathrm{GHz}$ to $2.480 \mathrm{GHz}$. These errors may be caused by the error of dielectric constant and manufacturing tolerances.

The dimensions of the proposed antenna are $13.50 \mathrm{~mm} \times$ $13.51 \mathrm{~mm} \times 0.8 \mathrm{~mm}$, namely, $0.11 \lambda_{0} \times 0.11 \lambda_{0} \times 0.0065 \lambda_{0}, \lambda_{0}$ is the wavelength in free space at the center frequency. For this antenna, the electrical size of the antenna $k a=0.49$, so it can be categorized to electrically small antenna strictly.

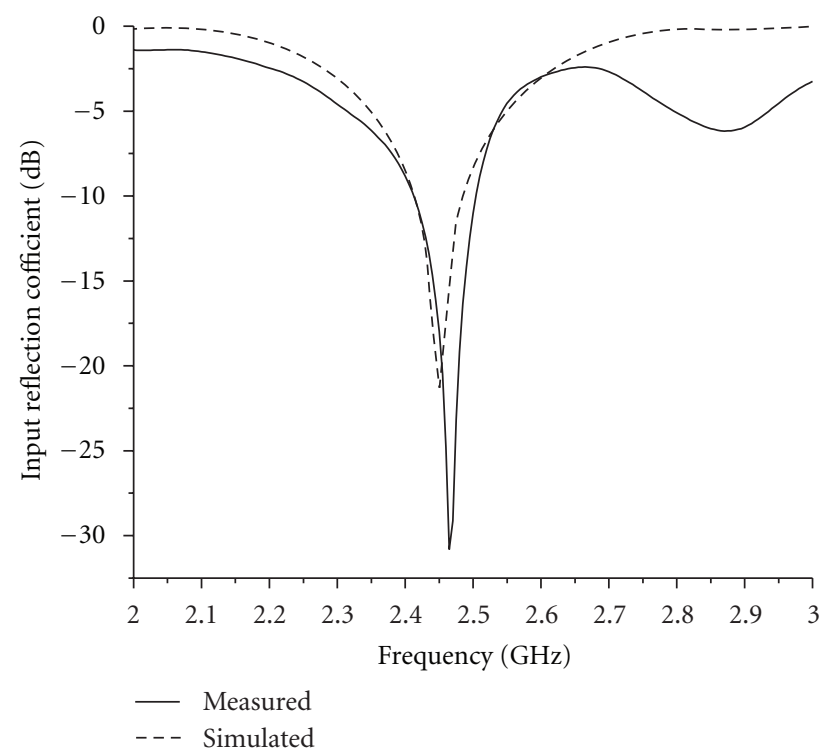

FIGURE 8: The simulated and measured input reflection coefficient.

As we known, when the electrical size of an antenna is small to a certain degree $(k a<0.5)$, it is difficult to make it smaller and maintain the same performance as well.

Radiation patterns of the proposed antenna are measured in a standard anechoic chamber. Simulated and measured radiation patterns in $\mathrm{H}$-plane and E-plane in the working bandwidth are shown in Figure 9. They are also roughly the same, and show a good omnidirectional radiation pattern is realized. The simulated gain as a function of frequency from $2.4 \mathrm{GHz}$ to $2.5 \mathrm{GHz}$ is shown in Figure 10 .

\section{Conclusion}

A novel electrically small antenna with a refined configuration of the trident-shaped feeding strip and the triangular slot stubs has been proposed in this paper. It has a simple structure based on a CPW feeding line and allows the use of low-cost and accurate planar print techniques. Precise prototyping and accurate measurement guarantee the veracity of 


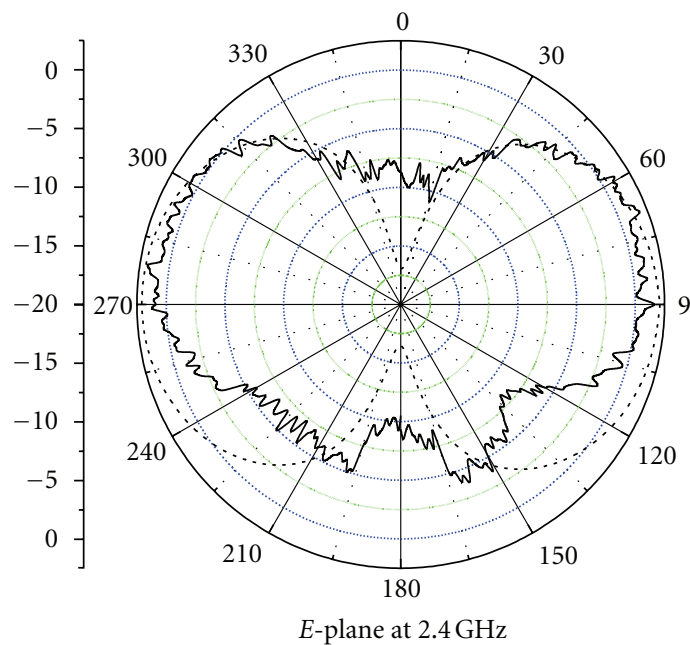

(a)

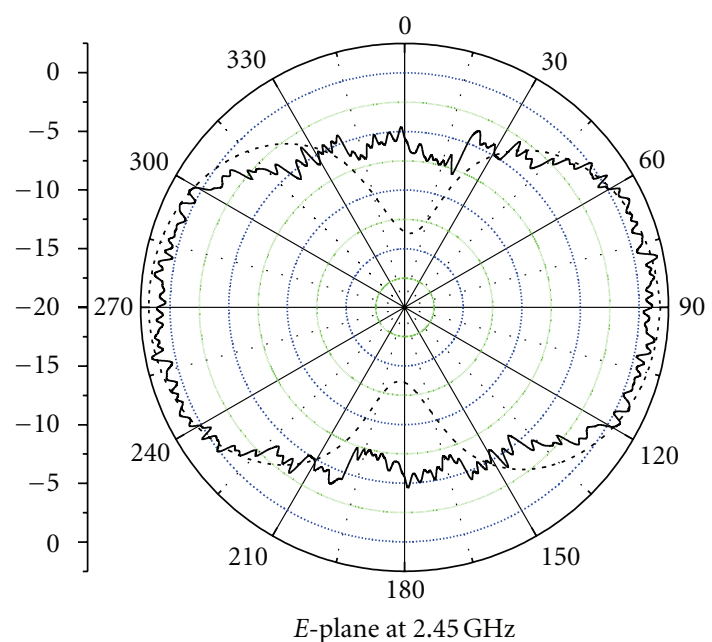

(c)

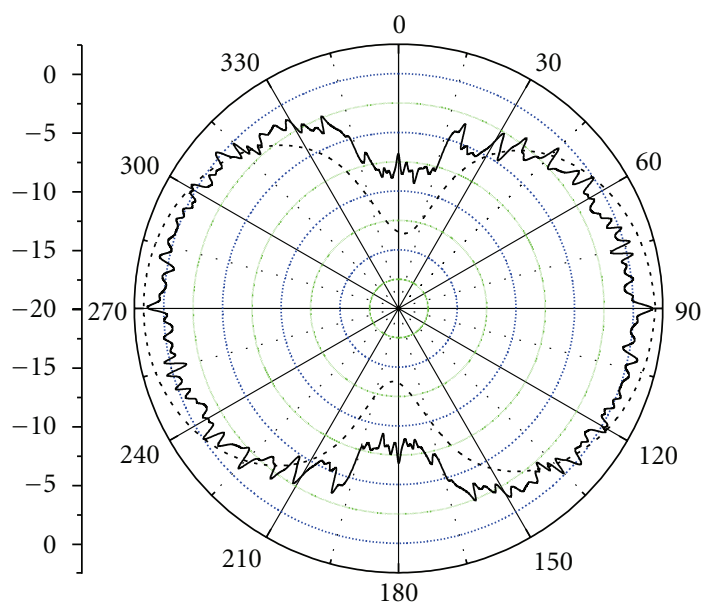

E-plane at $2.5 \mathrm{GHz}$

- - Simulated

— Measured

(e)

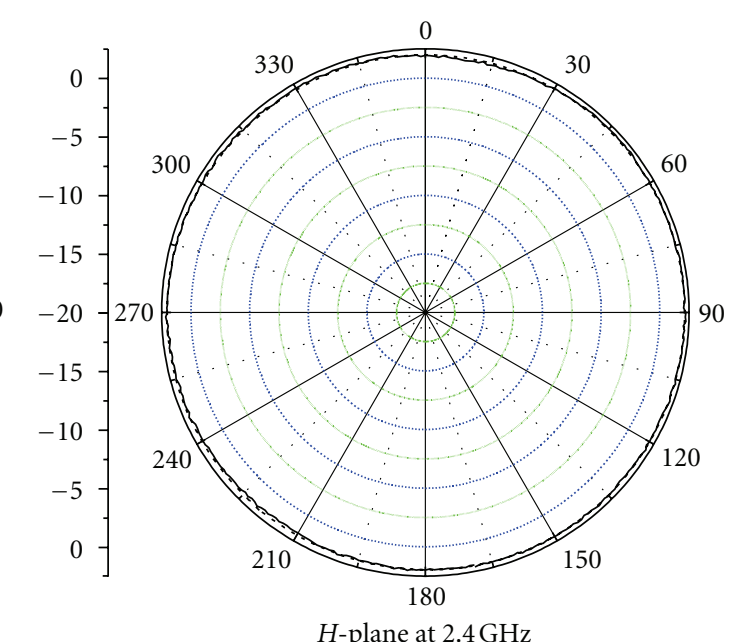

(b)

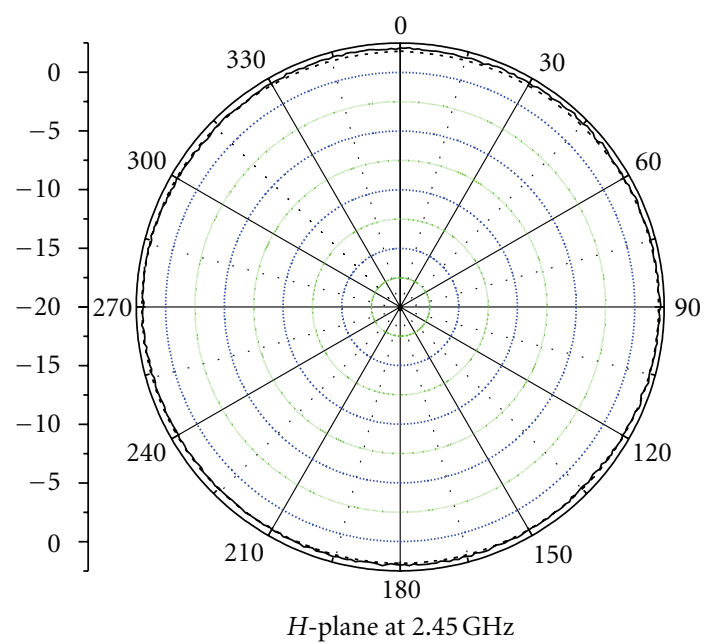

(d)



(f)

FIGURE 9: The radiation pattern of the proposed antenna in the working bandwidth. 


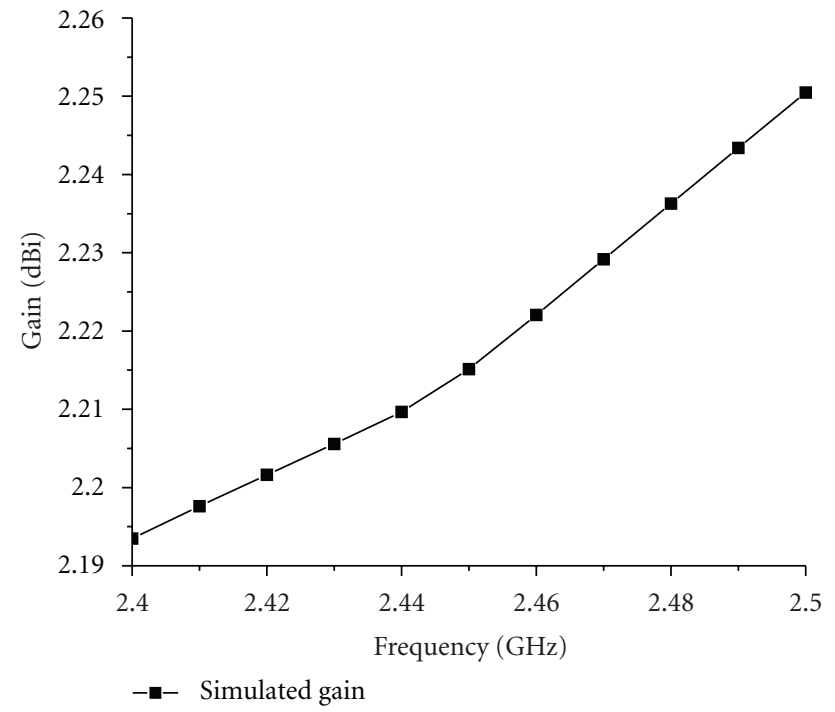

Figure 10: The simulated gain as a function of frequency from $2.4 \mathrm{GHz}$ to $2.5 \mathrm{GHz}$.

the results. It provides a $S_{11}<-10 \mathrm{~dB}$ bandwidth about $3.9 \%$ (from $2.410 \mathrm{GHz}$ to $2.505 \mathrm{GHz}$ ), and an input reflection coefficient of $-30.80 \mathrm{~dB}$ at the working frequency $2.46 \mathrm{GHz}$. The computed gain is up to $2.2 \mathrm{dBi}$ at $2.45 \mathrm{GHz}$. Those properties make this antenna to be a probable candidate for wireless communication applications.

\section{References}

[1] H. A. Wheeler, "Fundamental limitations of small antennas," Proceedings of the IRE, vol. 35, no. 12, pp. 1479-1484, 1947.

[2] H. R. Stuart and A. Pidwerbetsky, "Electrically small antenna elements using negative permittivity resonators," IEEE Transactions on Antennas and Propagation, vol. 54, no. 6, pp. 16441653, 2006.

[3] H. D. Foltz, J. S. McLean, and G. Crook, "Disk-loaded monopoles with parallel strip elements," IEEE Transactions on Antennas and Propagation, vol. 46, no. 12, pp. 1894-1896, 1998.

[4] H. Choo and H. Ling, "Design of electrically small planar antennas using inductively coupled feed," Electronics Letters, vol. 39, no. 22, pp. 1563-1565, 2003.

[5] E. E. Altshuler, "Electrically small self-resonant wire antennas optimized using a genetic algorithm," IEEE Transactions on Antennas and Propagation, vol. 50, no. 3, pp. 297-300, 2002.

[6] H. Choo, R. Rogers, and H. Ling, "Design of electrically small wire antennas using genetic algorithm taking into consideration of bandwidth and efficiency," in Proceedings of the IEEE Antennas and Propagation Society International Symposium, pp. 330-333, June 2002.

[7] M. S. Sharawi, Y. S. Faouri, and S. S. Iqbal, "Design and fabrication of a dual electrically small MIMO antenna system for 4G terminals," in Proceedings of the German Microwave Conference (GeMiC'11), pp. 1-4, March 2011.

[8] K. M. Chan, E. Lee, P. Gardner, and P. S. Hall, "A differentially fed electrically small antenna," in Proceedings of the IEEE Antennas and Propagation Society International Symposium (AP-S'07), pp. 2447-2450, Honolulu, Hawaii, USA, June 2007.

[9] P. Jin and R. W. Ziolkowski, "Multiband extensions of the electrically small, near-field resonant parasitic $\mathrm{Z}$ antenna," IET
Microwaves, Antennas and Propagation, vol. 4, no. 8, pp. 1016$1025,2010$.

[10] M. C. Scardelletti, G. E. Ponchak, S. Merritt, J. S. Minor, and C. A. Zorman, "Electrically small folded slot antenna utilizing capacitive loaded slot lines," in Proceedings of the IEEE Radio and Wireless Symposium (RWS'08), pp. 731-734, Orlando, Fla, USA, January 2008.

[11] F. Qureshi, M. A. Antoniades, and G. V. Eleftheriades, "A compact and low-profile metamaterial ring antenna with vertical polarization," IEEE Antennas and Wireless Propagation Letters, vol. 4, no. 1, pp. 333-336, 2005.

[12] Y. J. Kim, J. K. Kim, J. H. Kim, H. Y. Kim, and H. M. Lee, "Negative permeability metamaterial structure based electrically small loop antenna," in Proceedings of the 10th International Conference on Advanced Communication Technology (ICACT'08), pp. 769-773, Gangwon-Do, Korea, February 2008.

[13] P. S. Excell and N. McN Alford, "Superconducting electricallysmall dipole antenna," in Proceedings of the 7th International Conference on Antennas and Propagation (ICAP'91), pp. 446447, April 1991.

[14] Y. Tsutsumi, H. Kanaya, and K. Yoshida, "Design and performance of an electrically small slot loop antenna with a miniaturized superconducting matching circuit," IEEE Transactions on Applied Superconductivity, vol. 15, no. 2, pp. 1020-1023, 2005.

[15] An Introduction To HFSS, V12. 1, 1st edition, 2010.

[16] RO4000 laminates-Data sheet, Rogers corporation.

[17] A. K. Skrivervik, J. F. Zürcher, O. Staub, and J. R. Mosig, "PCS antenna design: the challenge of miniaturization," IEEE Antennas and Propagation Magazine, vol. 43, no. 4, pp. 12-27, 2001. 

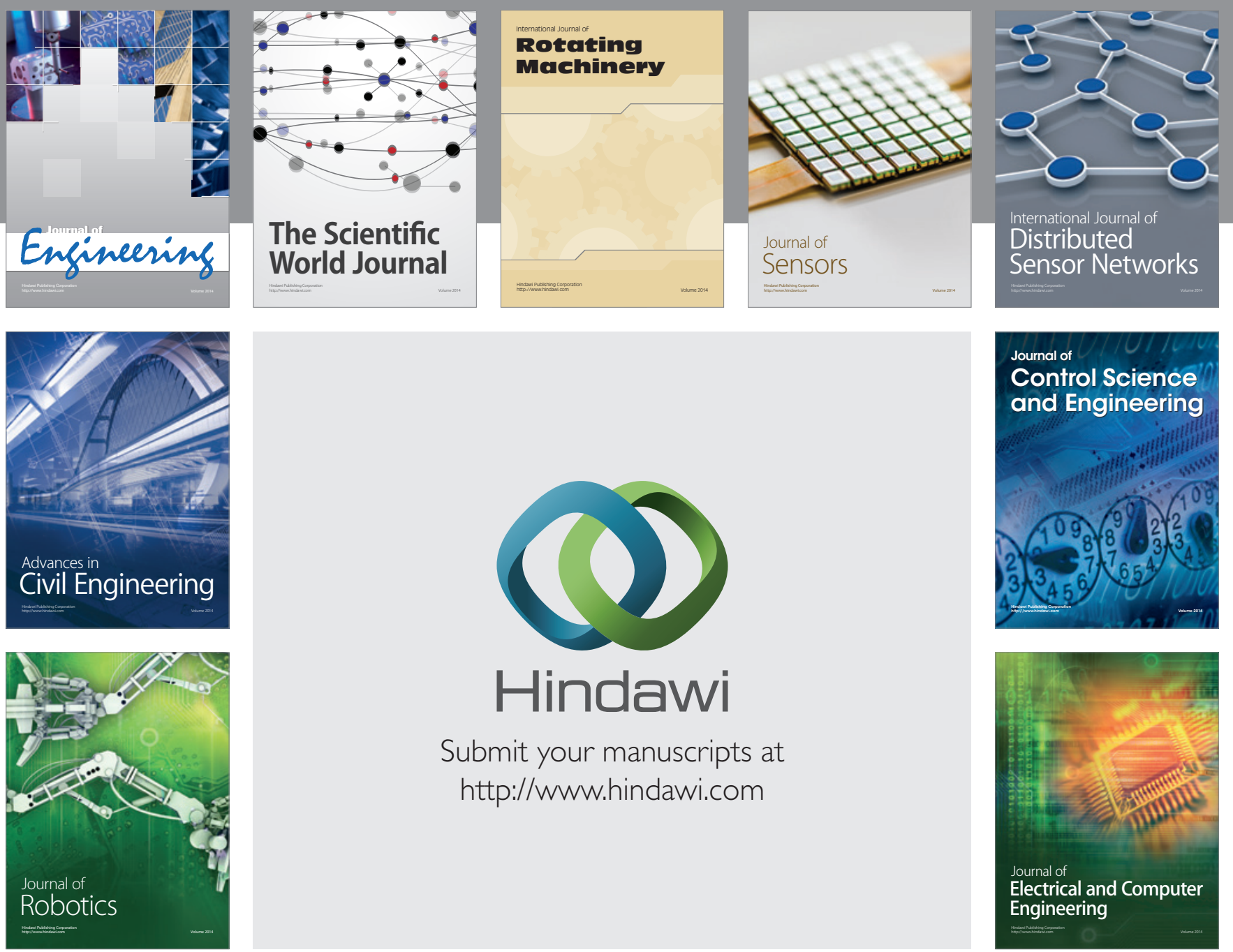

Submit your manuscripts at

http://www.hindawi.com
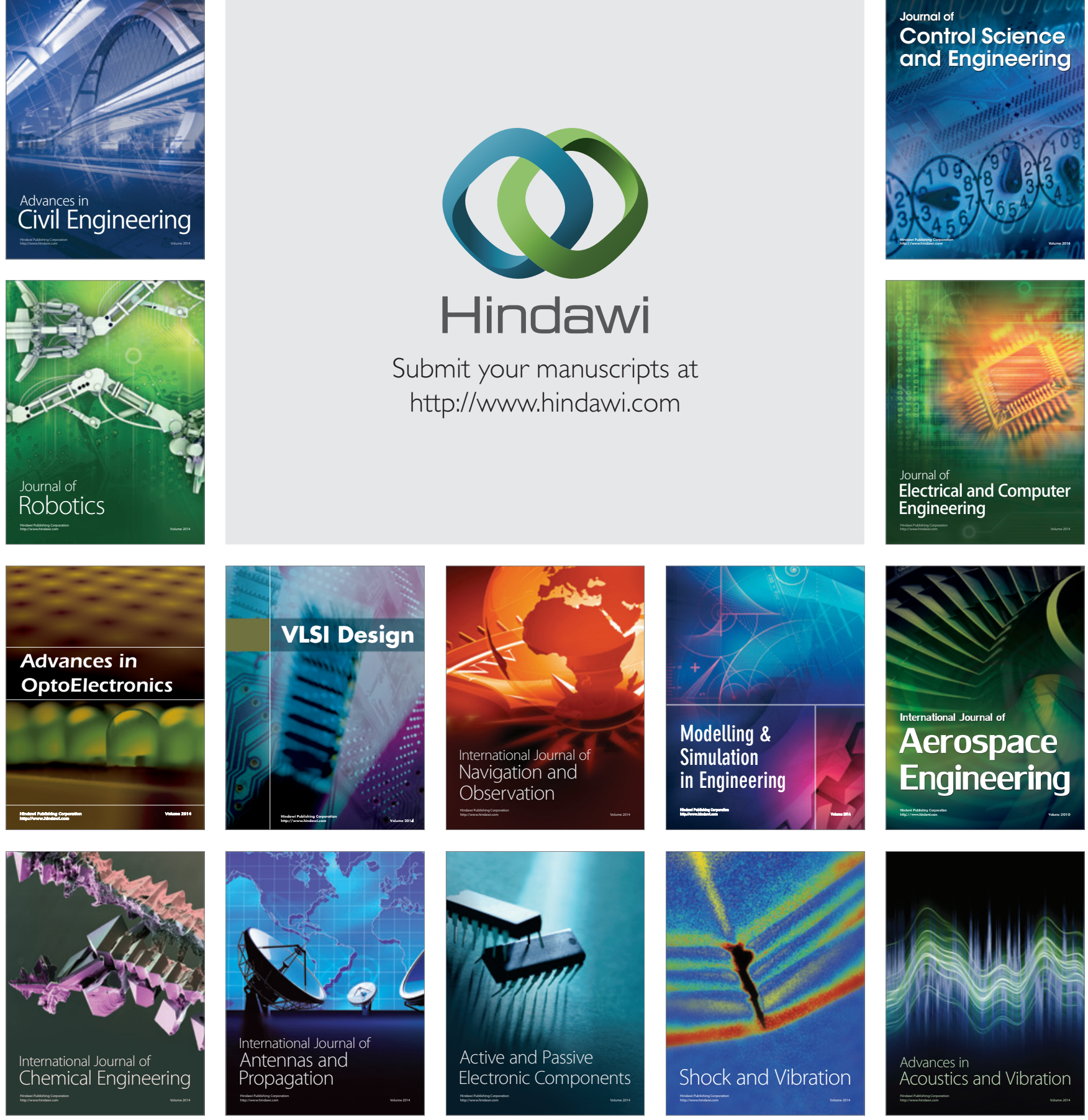